OPEN ACCESS

Edited by: Armida Mucci,

University of Campania Luigi

Vanvitelli, Italy

Reviewed by:

Caterina Adele Viganò,

University of Milan, Italy

Stefano Barlati,

University of Brescia, Italy

${ }^{*}$ Correspondence:

Lorenz B. Dehn

lorenz.dehn@evkb.de

Specialty section:

This article was submitted to Social Psychiatry and Psychiatric

Rehabilitation,

a section of the journal

Frontiers in Psychiatry

Received: 13 December 2021

Accepted: 10 January 2022

Published: 04 February 2022

Citation:

Dehn LB, Driessen M, Steinhart I and

Beblo T (2022) Participating in

Longitudinal Observational Research

on Psychiatric Rehabilitation:

Quantitative Results From a Patient

Perspective Study.

Front. Psychiatry 13:834389

doi: 10.3389/fpsyt.2022.834389

\section{Participating in Longitudinal Observational Research on Psychiatric Rehabilitation: Quantitative Results From a Patient
Perspective Study}

\author{
Lorenz B. Dehn ${ }^{1 *}$, Martin Driessen ${ }^{1,2}$, Ingmar Steinhart ${ }^{3,4}$ and Thomas Beblo ${ }^{1,2}$ \\ ${ }^{1}$ Department of Psychiatry and Psychotherapy, Evangelische Klinikum Bethel, Universitätsklinikum OWL of Bielefeld \\ University, Bielefeld, Germany, ${ }^{2}$ Department of Psychology, University of Bielefeld, Bielefeld, Germany, ${ }^{3}$ von \\ Bodelschwinghsche Stiftungen Bethel, Bielefeld, Germany, ${ }^{4}$ Institut für Sozialpsychiatrie Mecklenburg-Vorpommern e. V., \\ University of Greifswald, Greifswald, Germany
}

Background: Longitudinal observational studies play on an important role for evidence-based research on health services and psychiatric rehabilitation. However, information is missing about the reasons, why patients participate in such studies, and how they evaluate their participation experience.

Methods: Subsequently to their final assessment in a 2-year follow-up study on supported housing for persons with severe mental illness, $n=182$ patients answered a short questionnaire on their study participation experience (prior experiences, participation reasons, burden due to study assessments, intention to participate in studies again). Basic respondent characteristics as well as symptom severity (SCL-K9) were also included in the descriptive and analytical statistics.

Results: To help other people and curiosity were cited as the main initial reasons for study participation (>85\%). Further motives were significantly associated with demographic and/or clinical variables. For instance, "relieve from boredom" was more frequently reported by men and patients with substance use disorders (compared to mood disorders), and participants "motive" to talk about illness" was associated with higher symptom severity at study entry. Furthermore, only a small proportion of respondents indicated significant burdens by study participation and about $87 \%$ would also participate in future studies.

Conclusions: The respondents gave an overall positive evaluation regarding their participation experience in an observational study on psychiatric rehabilitation. The results additionally suggest that health and social care professionals should be responsive to the expectations and needs of patients with mental illness regarding participation in research.

Keywords: observational study, research participation, psychiatric rehabilitation, burden, evaluation, health service research 


\section{INTRODUCTION}

To improve and develop psychosocial health care and rehabilitation, empirical research is needed. This research relies, for a large part, on information that comes from the people who use social and medical support services. Overall, people with mental health problems seem to have positive attitudes toward psychiatric research and mostly indicate altruistic reasons for participation (1-5). However, patients' willingness to participate in research is influenced by different variables from three major domains (6): Sociocultural and demographic factors (e.g., age, gender); individual experiences and attitudes (e.g., prior research experience, general attitudes toward research), and clinical factors (e.g., diagnosis, severity of illness). Within this framework, participation is also influenced by specific characteristics of the study (6). For instance, in a study with $n=763$ psychiatric patients, Schäfer et al. (4) found a tendency to approve psychosocial (e.g., rehabilitation, role of the family) rather than biological research topics (e.g., genetics, biological treatments). In addition, "invasive" methods like medication trials achieved the lowest acceptance rate (58\%), while the highest willingness to participate was found for studies with questionnaires (91\%). Aside such general attitudes toward research, studies have, of course, also focused on the extent to which individuals with mental disorders are affected when participating in research projects. Here it has become apparent, that only a minority of participants in psychiatric research become distressed, but without evidence of longer-term harm (7). Although often considered with particular caution, this is as true for trauma-focused research in people with mental illness $(8,9)$. Nevertheless, researchers must of course be mindful that rates of adverse reactions might exceed those of community-based samples $(10,11)$.

For evidence-based research on health services and psychiatric rehabilitation, observational studies play an important role, because randomized controlled trials as the scientific gold standard may not be a feasible option under real-world community settings (12-14). Thus, the present study aims to address (a) what reasons motivate patients to participate in a longitudinal observational study on psychiatric rehabilitation? (b) What are the burdens for the study participants? (c) In how far are reasons and burdens associated with possible moderators such as socio-demographics, prior research experience, symptom severity or diagnostic group?

\section{METHODS}

\section{Study Setting}

Given the lack of systematic empirical research on supported housing for non-homeless people with severe mental illness, we conducted an observational follow-up study to compare clinical and functional outcomes of supported housing (SH) vs. residential care (RC) (15). In this prospective study, we included $n=257$ outpatients with severe mental illness, who were intended to enter $\mathrm{SH}$ or $\mathrm{RC}$ or had just entered one of these rehabilitation programs. The study project has been approved by the local IRB (University of Muenster Ethics Committee, 2017-149-f-S).

\section{Study Procedure}

The underlying observational study comprised three assessment time points across 2 years: Baseline at study entry (t1), intermediate assessment provided one year later ( $\mathrm{t} 2$ ), and final assessment after two years ( $\mathrm{t} 3$ ). Asides detailed documentation of socio-demographic and clinical variables at baseline, all three assessments included numerous questionnaires [e.g., Social Functioning Scale $(16,17)$; Manchester Short Assessment of Quality of Life (18), Symptom Checklist Shortform (19), Client Sociodemographic and Service Receipt Inventory (20, 21), Oxford Capabilities questionnaire-Mental Health (22), Camberwell Assessment of Need Short Appraisal Schedule (23, 24), short interview sections on psychosocial care and clinical course parameters, and a short cognitive skills test [TrailMaking-Test (25)]. Many instruments were available for selfcompletion. However, if patients pointed out any obstacles in doing so, the questionnaires were read aloud by the interviewers. Overall, a wide range of topics were addressed, e.g., daily living skills, mental health symptoms, social networks, life satisfaction, health care system, experiences with justice and police, drug use or family relationships. In general, the whole assessment procedure took about 60-90 min, depending on the how many breaks were taken or how detailed some questions were answered. In some cases, the assessment session took up to $2 \mathrm{~h}$ or was split into two appointments. Subsequent to the last assessment at the third study time point, participants were given a brief questionnaire to retrospectively evaluate their study participation experience (see below, measures).

\section{Participants}

Apart from age 18-69 years inclusion criteria into the underlying observational study were (i) a severe mental illness, diagnosed as defined by ICD-10 by a psychiatrist which (ii) lasted at least 2 years and (iii) was associated with a handicap that constitutes the right for supported housing according to the German social law IX. Exclusion criteria were non-sufficient German speaking and severe physical illness.

Prior to the first study assessment, outpatients were provided with detailed verbal and written study information, and gave their written informed consent to participate in the study. At the beginning of each study assessment, participants were reinformed about the study background and the options to skip parts of the study or to take a break at any time. The participants received a compensation of 10 Euros for the first and 20 Euros for each of the two following assessments.

$N=257$ individuals were initially included in the observational study, $n=56$ dropped out before the final assessment, $n=15$ declined to answer the study participation questionnaire, and $n=4$ individuals had over $50 \%$ missing values. Thus, the present study is based on data from $n=182$ participants. These enrolled respondents did not significantly differ from the group of dropped out and excluded patients in terms of gender $(p=0.780)$, diagnostic group $(p=0.166)$, psychopathological symptom burden $(p=0.733)$, or housing 
TABLE 1 | The evaluation questionnaire.

\begin{tabular}{ll}
\hline Questions/items (+ response options) & Origin/sources \\
\hline $\begin{array}{l}\text { A: Have you ever participated in a scientific } \\
\text { study before? (yes/no) }\end{array}$ & Schäfer et al. (4, 27) \\
$\begin{array}{l}\text { B: What have been your reasons for } \\
\text { participating in this study? }\end{array}$ & \\
B1: I was curious (yes/no) & Hall et al. 2018 (5) \\
B2: To help other people (yes/no) & Schäfer et al. (4), Hall \\
& et al. (5) \\
B3: Genuine interest in research (yes/no) & Schäfer et al. (4, 27) \\
B4: To get relieve from boredom (yes/no) & Schäfer et al. (4, 27) \\
B5: To talk about illness (yes/no) & Schäfer et al. (4, 27) \\
B6: Other people wanted me to do so (yes/no) & Hall et al. (5); Zullino \\
& et al. (1) \\
B7: Because of the monetary compensation & Schäfer et al. (4), \\
(yes/no) & Zullino et al. (1) \\
C1: How burdensome did you find the study & Question type and \\
assessments? & 5-Point-Likert-Scale \\
(not at all, a little bit, moderately, quite a bit, & based on established \\
very much) & scales [see (26)] \\
C2: If "quite a bit" or "very much": What was & \\
most burdening? & \\
(open response option) & \\
D: Would you consider taking part in studies in & Tallon et al. (28), \\
the future? & Boothyoyd et al. (10) \\
(yes, no, don't know) & \\
\hline
\end{tabular}

condition ( $p=0.330$ ), but they were on average slightly older $(M d=41.5, M=41.5 / \mathrm{SD}=12.9$ vs. $M d=35.0, M=37.9 / \mathrm{SD}=$ 13.6, $U=0.5689 .0, Z=-2.10, p=0.036)$.

\section{Measures}

\section{Sociodemographic and Clinical Data}

Sociodemographic and clinical information (e.g., age, occupational status, clinical diagnosis) was obtained by a structured interview and additional medical information provided by staff members of the psychiatric rehabilitation institutions during the baseline assessment. The burden of psychopathology was assessed via self-report by the 9-item Symptom Checklist [SCL-K-9 (19)], both at the first and the last assessment. We report the SCL-K9 mean score (0-4) as a Global Severity Index [GSI, (26)].

\section{Evaluation of Study Participation}

Subsequently to the final assessment, 2 years after the start of the index study, participants were asked to provide a retrospective evaluation of their study participation by means of a short questionnaire. To make data collection quick and easy, yesno questions were favored. Therefore, the applied questionnaire was compiled from single questions taken from existing scales [Hamburg Attitudes to Psychiatric Research Questionnaire (4, 27)] or previous studies, as can be seen in Table 1.

\section{Data Analysis}

In addition to baseline socio-demographic and clinical sample data, frequencies, and percentages were obtained for all items of the study participation questionnaire. Using the response categories (e.g., yes vs. no), appropriate group comparisons were then performed with respect to possible influencing factors. For this, we selected the following variables according to the three domains from the model by Pfeiffer et al. (6): age and gender (sociocultural and demographic factors); prior research experience (individual experiences and attitudes), diagnosis, symptom severity at study entry and after 2 years, distress due to study participation (clinical factors). Additionally, the type of supported accommodation was also included to control for possible influences by the purpose of the underlying study.

Depending on variable scaling and distribution, parametric $\left(t\right.$-Test) or non-parametric (Mann-Whitney-Test, Chi ${ }^{2}$-Test) statistical tests were applied. Normal distribution assumption for metric data was checked using Kolmogorov-Smirnov test. Data was analyzed using SPSS Statistics, version 25. The general significance level was set to 0.05 and two-tailed.

\section{RESULTS}

\section{Participant Characteristics}

Demographic and clinical characteristics of the participants are provided in Table 2. The most prevalent primary diagnosis among the sample were substance-related disorders $(29.1 \%)$, mood disorders (22.5\%), and schizophrenic disorders (19.2\%). However, about $75 \%$ of the participants also had comorbid psychiatric diagnoses, and about two-thirds had additional (chronic) physical impairments or acute somatic conditions. As could be expected, the average burden of psychopathological symptoms in the participants at baseline and after 2 years was about two standard deviations above the values for a representative population sample [Global Severity Index/GSI: $M$ $=0.41, S D=0.51, N=2,057$; (19)], but within the range of increased values typically found in psychiatric inpatients [e.g., GSI: $M=1.7, S D=0.83, N=2,727 ;(26)]$.

\section{Evaluation of Study Participation Total Sample}

As can be seen in Table 3, around $71 \%$ of all participants indicated that they had never participated in a scientific study before. The main reasons for study participation in retrospect have been to help other people $(86.8 \%)$, curiosity $(85.2 \%)$, and a genuine interest in research (73.6\%). The reasons "relief from boredom" (41.8\%) and "an opportunity to talk about illness" $(48.4 \%)$ were overall affirmed by almost one in two. The prospect of monetary compensation for participation played a role for more than one-third of individuals (35.7\%), and one in ten felt prompted to participate by others $(10.4 \%)$. More than half of the whole sample $(58.8 \%)$ did not feel burdened in any way by participating in the study and its repeated assessment procedures. Only $<5 \%(n=9)$ of the participants indicated that they had felt "quite a bit" or "very much" burdened. Of these respondents, $n$ $=7$ people provided information about what had burdened them the most: too many questions (twice), too long surveys, dealing with uncomfortable issues, questions about sexuality, questions about family, reflecting on one's health status using numbers. At the end of the questionnaire, a large proportion of respondents 
TABLE 2 | Demographic and clinical characteristics of the participants.

\begin{tabular}{|c|c|c|}
\hline Variable & & $\%(n)$ \\
\hline Gender & Female & $41,2 \%(75)$ \\
\hline \multirow[t]{2}{*}{ Age } & Mean (SD) & 41.5 (12.9) \\
\hline & Median (Min-Max) & $41.5,20-68$ \\
\hline \multirow[t]{2}{*}{$\begin{array}{l}\text { Type of supported } \\
\text { accommodation }\end{array}$} & $\begin{array}{l}\text { Residential care (with staff } \\
\text { on site) }\end{array}$ & $38.5 \%(70)$ \\
\hline & $\begin{array}{l}\text { Supported housing (in own } \\
\text { apartment) }\end{array}$ & $61.5 \%(112)$ \\
\hline \multirow[t]{6}{*}{$\begin{array}{l}\text { ICD-10 diagnostic } \\
\text { category }\end{array}$} & $\begin{array}{l}\text { F1: Substance-related } \\
\text { disorders }\end{array}$ & $29.1 \%(53)$ \\
\hline & F2: Schizophrenic disorders & $19,2 \%$ (35) \\
\hline & F3: Mood disorders & $22.5 \%(41)$ \\
\hline & $\begin{array}{l}\text { F4: Anxiety, stress-related } \\
\text { and somatoform disorders }\end{array}$ & $10.4 \%(19)$ \\
\hline & $\begin{array}{l}\text { F6: Disorders of personality } \\
\text { and behavior }\end{array}$ & $11.5 \%(21)$ \\
\hline & $\begin{array}{l}\text { Other mental and behavioral } \\
\text { disorders }\end{array}$ & $7.1 \%(13)$ \\
\hline \multirow{2}{*}{$\begin{array}{l}\text { Symptom severity } \\
\text { (SCL-K9) baseline }^{a}\end{array}$} & Mean GSI-score (SD) & $1.5(1.0)$ \\
\hline & Median (Min-Max) & $1.4(0-4)$ \\
\hline \multirow{2}{*}{$\begin{array}{l}\text { Symptom severity } \\
\text { (SCL-K9) after } 2 \text { years }^{\text {b }}\end{array}$} & Mean GSI-score (SD) & $1.3(1.0)$ \\
\hline & Median (Min-Max) & $1.1(0-4)$ \\
\hline
\end{tabular}

$a_{n}=178,{ }^{b} n=181$.

TABLE 3 | Subjective evaluation of study participation $(\%, n)$.

\begin{tabular}{lccc}
\hline & Yes & No & Missing \\
\hline Prior study participation & $23.6 \%(43)$ & $70.9 \%(129)$ & $5.5 \%(10)$ \\
Reasons for participating in the study & & \\
To help other people & $86.8 \%(158)$ & $11.5 \%(21)$ & $1.6 \%(3)$ \\
I was curious & $85.2 \%(155)$ & $14.8 \%(27)$ & - \\
Genuine interest in research & $73.6 \%(134)$ & $23.6 \%(43)$ & $2.7 \%(5)$ \\
To talk about illness & $48.4 \%(88)$ & $47.8 \%(87)$ & $3.8 \%(7)$ \\
To get relieve from boredom & $41.8 \%(76)$ & $56.0 \%(102)$ & $2.2 \%(4)$ \\
Because of the monetary & $35.7 \%(65)$ & $62.1 \%(113)$ & $2.2 \%(4)$ \\
compensation & & & \\
Other people wanted me to do so & $10.4 \%(19)$ & $87.4 \%(159)$ & $2.2 \%(4)$ \\
Burden due to study participation $(\boldsymbol{n}=\mathbf{1 8 1})$ & & \\
Not at all & $58.8 \%(107)$ & & \\
A little bit & $24.2 \%(44)$ & & \\
Moderately & $11.5 \%(21)$ & & \\
Quite a bit & $4.4 \%(8)$ & & \\
Very much & $0.5 \%(1)$ & & \\
Would participate in study again & $87.4 \%(159)$ & $1.6 \%(3)$ & \\
( $\boldsymbol{n}=\mathbf{1 8 0})$ & & & \\
\hline
\end{tabular}

(87\%) indicated that they would like to participate in studies again in the future.

\section{Influential Factors}

To be consistent with the dichotomous yes-no questions and to compensate group sizes, the response categories for the burden item (not at all vs. a little bit/ moderately/ quite a bit/ very much) and the re-participation question (yes vs. no/don't know) have been dichotomized for the following analyses. Moreover, nonparametric Mann-Whitney tests were used, because of partially unbalanced group sizes and non-normally distributed metric variables in several subgroups (KS-Test: $p<0.05$ ).

Age

For all evaluation items, there were no differences in age between response categories $(p>0.05)$, except for the participation reason "Other people wanted me to do so". Here, those $n=19$ participants who said they had initially attended because of others were on average somewhat older, than those who denied this item $(\mathrm{Md}=53.0, M=47.4 / \mathrm{SD}=14.3 \mathrm{vs} . \mathrm{Md}=41.0, M=41.1 / \mathrm{SD}=$ 12.6, $U=1070.0, Z=-2.08, p=0.037)$.

\section{Gender}

A significant difference with respect to gender occurred only for the participation reason "To get relieve from boredom" $\left(\mathrm{Chi}^{2}=6.33\right.$, Phi $\left.=-0.189, p=0.014\right)$. Here, men $(50.5 \%)$ were significantly more likely to affirm this reason than women $(31.5 \%)$.

\section{Supported Accommodation Type}

The questionnaire responses did not show any significant differences between persons from Residential Care or Supported Housing $(p=0.339-1.00)$.

\section{Prior Research Participation}

There were no significant differences between persons with and without prior experience in either the various reasons for participation ( $p=0.107-1.00$ ) nor the level of burden experienced $(p=1.00)$. Among those persons who had never participated in research before, the proportion who would consider a further study participation $(90.7 \% / n=117)$ did not significantly differ from the group with prior experience $(92.9 \% / n$ $=39, p=0.766)$.

\section{Clinical Diagnosis}

Analyses of possible differences by diagnosis were at first based on the existing five distinct ICD-10-diagnosis groups (see Table 2). The items of the evaluation questionnaire did not show any significant differences depending on the diagnostic group ( $p=$ $0.063-0.931$ ), apart from a tendency regarding the participation reason "To get relieve from boredom" $(p=0.063)$. However, this trend became statistically significant $\left(\mathrm{Chi}^{2}=8.35\right.$, Phi $=$ $0.257, p=0.015$ ) when the analyses were based solely on the three most frequent diagnosis groups (F1-F3, 71\% of the total sample). Subsequent post-hoc subgroup analyses with adjusted significance level $(0.05 / 3=0.0167)$ showed the following results: In the substance-use disorders group, it was significantly more often reported to have participated as a relieve from boredom than in the mood disorders group $(54.9 \% / n=28$, vs. $25 \% / n=$ $10, \mathrm{Chi}^{2}=8.24$, Phi $\left.=-0.301, p=0.005\right)$. When comparing the mood vs. schizophrenic disorder group, there was only a slight trend ( $p=0.088$ ), but no difference appeared between the schizophrenic and substance-related disorders group (45,7\%/n $=16$ vs. $54.9 \%, p=0.511)$. Since the participation reason 
"To get relieve from boredom" has also been associated with gender (see above), possible gender-related effects depending on diagnosis group were exploratively examined, but without significant results $(p=0.120-1.00)$.

\section{Symptom Severity}

The level of psychopathological symptom severity assessed at the last study interview and thus at the same time point as the evaluation questionnaire, showed no associations with prior research experience, the various reasons for participation, participation burden, or further participation interest $(p=0.199$ $0.996)$. However, when the symptom severity from study entry was taken into account, the following significant relationship emerged: Those respondents who agreed with the participation reason "To talk about ilness" ( $n=88 / 48.4 \%$ ) had higher baseline symptom severity scores than persons who denied this reason $(M d=1.33, M=1.36 / S D=0.88$ vs. $M d=1.72, M=1.74 / S D$ $=1.04, U=2892.5, Z=-2.35, p=0.018)$.

\section{Burden Due to Study Participation}

Not any socio-demographic or clinical variable and none of the different reasons for participation were significantly associated with the level of burden due to participation $(p=0.078-1.00)$. However, among those respondents who felt at least somewhat burdened ( $n=73$ ), significantly fewer persons were willing to participate in a study again compared with those who felt not burdened at all (80.8 vs. $94.3 \%, \mathrm{Chi}^{2}=7.96$, $\mathrm{Phi}=0.206, p$ $=0.007$ ).

\section{DISCUSSION}

Long-term observational studies provide an important basis for empirical research in psychiatric rehabilitation and mental health service care. However, little known about how people with severe mental illnesses evaluate their actual experience of participation in such observational studies.

\section{General Evaluation and Experienced Burden}

The present results from a 2-year observational study reveal an overall positive evaluation outcome with participants favorably responding with respect to their research experience. For instance, while about $71 \%$ of the patients had never participated in a study before, at the end almost $90 \%$ indicated that they would consider participating in future research. This proportion of $90 \%$ roughly corresponds to the $86 \%$ from a study on managed care in severe mental illness (10), but it was even somewhat higher than the $75 \%$ from a RCT on antidepressant medication (28). Moreover, in our study this proportion did not differ between persons with and without previous research experience, so it can be concluded that even patients participating in research for the first time ever gained a good impression from their experiences in a longitudinal observational study. In their paper " That was helpful... no one has talked to me about that before': Research participation as a therapeutic activity," Lakeman et al. (29) argued that psychiatric research participation involves processes that are frequently therapeutic in nature or often benefit participants, e.g. telling and retelling details about an aspect of one's life to a researcher.

The majority of participants was not affected by the repeated comprehensive study assessments and did not feel burdened by them at all. Only 5\% reported feeling quite a bit or very much burdened. Despite different scaling and reverse polarity, these results are largely consistent with data form an earlier study by Boothyroyd (10). At that time, $n=523$ participants with a severe mental illness were asked to rate their overall research experience after participating in a 12 -months managed care study. While $96 \%$ of the respondents indicated that it was a (very, somewhat, slightly) positive experience, $4 \%$ perceived it as a (slightly, somewhat, very) negative experience. Furthermore, Jorm et al. (7) have performed a systematic review on whether participation in studies that involved (questionnaire) assessment of symptoms, prevalence or risk factors of psychiatric disorders causes distress. The reviews main conclusion was that only " $a$ minority of participants (generally $<10 \%$ ) experience distress" (p. 919).

In our study, the participation burden was neither related to socio-demographic nor to clinical variables, like diagnosis or symptom severity. Although participation-related distress has been found to be associated with poorer mental health and more symptom severity (7), our results are in line with other studies, that found no association between study distress and psychopathology $(9,30)$. Thus, the present findings may indicate that longitudinal observational research in the field of psychiatric rehabilitation can be conducted with a variety of patients with diverse clinical (and socio-demographic) characteristics. Nonetheless, our results also showed that there might remain a risk that persons who felt some form of burden from research participation will not enroll in future studies. Even if this only refers to rather few cases, this finding highlight that (negative) previous experiences with research can have an impact on future study participation [see also $(31,32)$ ].

\section{Reasons for Participation and Their Moderators}

Consistent with other research, our results showed that the most frequently reported reason for initial study participation was to help other people [e.g., $(2,27,33)]$. Although motivation for study participation is a multi-dimensional construction (6), altruism has been identified to be one of the most relevant factors in medical research settings [e.g., $(34,35)]$.

In the present study, the least frequent indicated reason for research participation was "Others wanted me to do so." It is notable here, that those few people who cited this reason were slightly older than the rejecters. It could be possible, that older people may have felt more urged to participate, because older age in psychiatric patients has not only been found to be associated with a worse understanding of clinical trial proposals (36), but also with a more frequent refusal of research participation $(37,38)$. However, these results are somewhat limited because the respondents in the present study were also somewhat older overall than those who were not enrolled in the retrospective evaluation (see Participants). 
With respect to the other reasons for participation, curiosity, to help others, research interest, and monetary compensation showed no correlations with one of the influencing variables examined. However, "to get relieve from boredom" was associated with male gender and having substance use disorders (as compared to mood disorders). A higher prevalence of boredom experience among men than woman has also been confirmed by large community-based studies (39-41). Moreover, for inand outpatients with different mental illnesses the experience of boredom is common and of particular relevance to their quality of life (42-45). Thus, distraction from boredom was also cited equally often as a hypothetical reason for research participation by patients with depression and schizophrenia (4). Our results confirm this finding, but additionally point to the relevance of boredom distraction as a salient reason for research participation in substance-use disorder patients. Distracting boredom plays a prominent role in managing symptoms of illness for these patients, as boredom has been identified being among the most common aversive experiences linked to withdrawal symptoms and relapse reasons (46-48).

Finally, those persons who agreed with the reason "to talk about my illness" had higher symptom severity ratings at study entry than those who disagreed. Here, one can come to the conclusion that the possible benefit of being able to talk about the illness might have prompted initially more severely ill individuals to participate in the observational study. This could possibly related to social isolation and feelings of loneliness that are common among people with severe mental illness (49) and can be of major concern even under supported housing settings (50). Data form a recent clinical study has shown, that more severe psychopathological symptoms in persons with a mental illness are correlated with greater loneliness, even when objective social isolation, socio-demographic and clinical confounders were controlled for (51). Although we did not assessed loneliness here, the present results can be interpreted in the sense that the greater the symptom burden, the greater the loneliness, and thus participating in a psychosocial research study opens up an occasion to talk to someone "from outside" about one's own mental health problems. This is supported by an interviewstudy by Woodall et al. (52), in which the prospect of talking to other people about their experiences has been found to act as a facilitator for research participation in people with a firstepisode psychosis.

\section{Implications for Research Practice}

The present results have shown that even when participating in a longitudinal observational study with repeated and comprehensive psychosocial assessments, only a minority of participants become distressed, thus strengthening empirical findings from previous studies $(7,53)$. This is of particular importance because during the initiation of psychiatric studies the appropriateness of the research is often questioned with respect to the vulnerability of the targeted patients (54). For instance, in their systematic review on the experiences of vulnerable people participating in research on sensitive topics, Alexander et al. (55) have concluded that although "there is little evidence of harm to participants... researchers frequently experience obstacles and the phenomenon known as "gatekeeping" when attempting to conduct research amongst vulnerable populations" (p. 1). Howard et al. (56) identified paternalism as one of the major recruitment difficulties during an RCT of supported employment for people with severe mental illness. Through interviews, the authors were able to figure out, that mental health care coordinators were focusing more on their perception of patient needs than providing patients with the opportunity to decide whether they would like to participate in research. Therefore, the authors have concluded that due to such paternalistic attitude patients were often denied access to research trials (56). Hughes-Morley et al. (57) have conducted a meta-synthesis on factors affecting recruitment into depression trials, and they identified a "protecting the vulnerable patient" theme among the literature. This means, from the perspective of professional gatekeepers, patients with depression were typically seen as vulnerable, with the need to be protected against an additional burden due to research participation. However, the present findings clearly show that the majority of participants do not feel burdened by the repeated comprehensive study assessments. Moreover, the results suggest, that longitudinal observational research can be conducted with psychiatric outpatients with various clinical and sociodemographic characteristics. In addition to general motives such as altruism and curiosity, research participation depends on certain clinical characteristics. For instance, reducing boredom through study participation might be of particular relevance for substance-use disorder patients, and being able to talk about one's illness appears to be a motivator for patients with more severe symptoms. Thus, honorable and well-intentioned, paternalistic gatekeeping and overprotection by health care professionals could hinder patients from fulfilling their personal motives for research participation (55). Besides such barriers for individual participation, this may also lead to constraints in scientific outcomes. If patients are withheld from study participation because of overestimated negative effects, this can impact data variance and thus weaken the strength of empirical results.

\section{Limitations}

Instead of assessing motives for a hypothetical willingness to participate in psychiatric research $(1,2,4)$, the present study asked in retrospect about the reasons for participating in a longitudinal rehabilitation study. However, this comes along with the constraint, that such retrospective assessments may be imprecise due to recall bias (58). Thus, the reasons mentioned for participation might not necessarily have been the initial motives, but were rather influenced by the study experience. If questions on participation reasons would already be implemented at study baseline, then this could not only allow comparison with later retrospective questions on participation reasons, but might also offer interesting insights for detailed analysis of drop-outs. Another limitation of the present study is that the results were gathered as part of a research project on supported housing for people with mental disorders. Although these housing conditions of the index study did not appear to have affected the target parameters, the results should nevertheless be validated in other areas of social psychiatric rehabilitation, such as work, 
leisure time, or social participation. Moreover, future studies should also be more differentiated in assessing the burden of study participation, instead of just asking about "burden" in general, as it was done in the present questionnaire. For instance, Wenemark et al. (59) have identified five categories of respondent burden in health-related surveys: Cognitive burden (e.g., difficult to understand), unnecessary work (e.g., repetitive questions), distrust (e.g., manipulation), offending questions (e.g., too personal), and distress (e.g., worry, sadness). In addition, a parallel rating by care coordinators regarding the potential burden of study participation on their patients, would allow further interesting analysis of self- and proxy perceptions on this issue. Last but not least, future studies should also ask in more detail about potential benefits from study participation.

\section{CONCLUSIONS}

Outpatients with a severe mental illness gave an overall positive evaluation regarding their participation in a 2 -year observational rehabilitation study. The majority reported no burden associated with the repeated comprehensive psychosocial assessments, and there was a high willingness to participate in studies again. Altruism and curiosity were cited as the most important reasons for participation in retrospect, and some of the participation motives were associated with socio-demographic and clinical variables. All in all, the burdens of research participation for patients with mental illness should not be overestimated by health and social care professionals. This is not only important in terms of adequately addressing the patients' needs, but also for generating valid scientific results.

\section{DATA AVAILABILITY STATEMENT}

The dataset presented in this article is not readily available due to formal data protection reasons, the anonymized dataset of the present study is only available from the corresponding author on reasonable request.

\section{REFERENCES}

1. Zullino D, Conus P, Borgeat F, Bonsack C. Readiness to participate in psychiatric research. Can J Psychiatry. (2003) 48:480-4. doi: 10.1177/070674370304800709

2. Edlinger $M$, Deisenhammer EA, Fiala $M$, Hofer A, Kemmler G, Strauß R, et al. Attitudes of patients with schizophrenia and depression towards psychiatric research. Psychiatry Res. (2010) 177:172-6. doi: 10.1016/j.psychres.2008.12.010

3. Taylor PJ, Awenat Y, Gooding P, Johnson J, Pratt D, Wood A, et al. The subjective experience of participation in schizophrenia research: a practical and ethical issue. J Nerv Ment Dis. (2010) 198:343-8. doi: 10.1097/NMD.0b013e3181da8545

4. Schäfer I, Burns T, Fleischhacker WW, Galderisi S, Rybakowski JK, Libiger J, et al. Attitudes of patients with schizophrenia and depression to psychiatric research: a study in seven European countries. Soc Psychiatry Psychiatr Epidemiol. (2011) 46:159-65. doi: 10.1007/s00127-0100181-7

5. Hall J, Rus-Calafell M, Omari-Asor L, Ward T, Emsley R, Garety $\mathrm{P}$, et al. Assessing the subjective experience of participating
Requests to access the dataset should be directed to Lorenz B. Dehn, lorenz.dehn@evkb.de.

\section{ETHICS STATEMENT}

The studies involving human participants were reviewed and approved by University of Muenster Ethics Committee, 2017-149-f-S. The patients/participants provided their written informed consent to participate in this study.

\section{AUTHOR CONTRIBUTIONS}

LD conceived and planned the research project, was involved in data collection, performed the statistical analyses, and drafted the original manuscript. MD supervised the study project and participated in manuscript preparation. IS was the project leader of the supported housing study and reviewed the article for publication. TB has oversight for the research activity, and critically reviewed the manuscript draft. All authors read and approved the final manuscript.

\section{FUNDING}

This study on supported housing was supported by a grant from the Stiftung Wohlfahrtspflege NRW (Welfare Foundation North Rhine-Westphalia). The authors confirm, that this foundation had no influence on study design, data interpretation or writing the manuscript. We acknowledge the financial support of the German Research Foundation (DFG) and the Open Access Publication Fund of Bielefeld University for the article processing charge.

\section{ACKNOWLEDGMENTS}

We are grateful to all participants who volunteered for this study. We also thank all colleagues from the project team for helping us during the research project. in a clinical trial (AVATAR). Psychiatry Res. (2018) 263:827. doi: 10.1016/j.psychres.2018.02.026

6. Pfeiffer PN, Szymanski B, Dhawan N, DiFranco D, Valenstein M, Zivin K. Is there an "unhealthy volunteer effect" in mental health outpatient research? Psychiatry Res. (2010) 176:224-8. doi: 10.1016/j.psychres.2009.07.016

7. Jorm AF, Kelly CM, Morgan AJ. Participant distress in psychiatric research: a systematic review. Psychol Med. (2007) 37:91726. doi: 10.1017/S0033291706009779

8. Jaffe AE, DiLillo D, Hoffman L, Haikalis M, Dykstra RE. Does it hurt to ask? A meta-analysis of participant reactions to trauma research. Clin Psychol Rev. (2015) 40:40-56. doi: 10.1016/j.cpr.2015.05.004

9. Grubaugh AL, Tuerk PW, Egede LE, Frueh BC. Perceptions of PTSD research participation among patients with severe mental illness. Psychiatry Res. (2012) 200:1071-3. doi: 10.1016/j.psychres.2012.07.039

10. Boothroyd RA. The impact of research participation on adults with severe mental illness. Ment Health Serv Res. (2000) 2:213-22. doi: 10.1023/A:1010112503631

11. Tan DP, Morgan AJ, Jorm AF, Reavley NJ. Emotional impacts of participation in an Australian national survey on mental health-related discrimination. Ethics Behav. (2019) 29:438-58. doi: 10.1080/10508422.2019.1593844 
12. Barnish MS, Turner S. The value of pragmatic and observational studies in health care and public health. Pragmat Obs Res. (2017) 8:4955. doi: 10.2147/POR.S137701

13. Bonell CP, Hargreaves J, Cousens S, Ross D, Hayes R, Petticrew M, et al. Alternatives to randomisation in the evaluation of public health interventions: design challenges and solutions. J Epidemiol Community Health. (2011) 65:582-7. doi: 10.1136/jech.2008.082602

14. Anglemyer A, Horvath HT, Bero L. Healthcare outcomes assessed with observational study designs compared with those assessed in randomized trials. Cochrane Database Syst Rev. (2014). doi: 10.1002/14651858.MR000034.pub2

15. Dehn LB, Beblo T, Richter D, Wienberg G, Kremer G, Steinhart I, et al. Effectiveness of supported housing versus residential care in severe mental illness: a multicenter, quasi-experimental observational follow-up study. $S o c$ Psychiatr Psychiatr Epidemiol. (2022). doi: 10.1007/s00127-021-02214-6

16. Birchwood M, Smith JO, Cochrane R, Wetton S, Copestake S. The social functioning scale: the development and validation of a new scale of social adjustment for use in family intervention programmes with schizophrenic patients. Br J Psychiatry. (1990) 157:853-9. doi: 10.1192/bjp.157.6.853

17. Iffland JR, Lockhofen D, Gruppe H, Gallhofer B, Sammer G, Hanewald B. Validation of the German version of the social functioning scale (SFS) for Schizophrenia. PLoS ONE. (2015) 10:e0121807. doi: 10.1371/journal.pone.0121807

18. Priebe S, Huxley P, Knight S, Evans S. Application and results of the manchester short assessment of quality of life (MANSA). Int $J$ Soc Psychiatry. (1999) 45:7-12. doi: 10.1177/002076409904500102

19. Klaghofer R. Brähler E. [Construction and test statistical evaluation of a short version of the SCL-90-R]. Zeitschrift für Klinische Psychologie, Psychiatrie und Psychotherapie. (2001) 49:115-24.

20. Roick C, Kilian R, Matschinger H, Bernert S, Mory C, Angermeyer MC. German adaptation of the client sociodemographic and service receipt inventory-an instrument for the cost of mental health care. Psychiatr Prax. (2001) 28:S84-90. doi: 10.1055/s-2001-17790

21. Chisholm D, Knapp MRJ, Knudsen HC, Amaddeo F, Gaite L, Van Wijngaarden $\mathrm{BOB}$, et al. Client socio-demographic and service receipt inventory-European version: development of an instrument for international research: EPSILON Study 5. Br J Psychiatr. (2000) 177:s28-33. doi: 10.1192/bjp.177.39.s28

22. Simon J, Łaszewska A, Leutner E, Spiel G, Churchman D, Mayer S. Cultural and linguistic transferability of the multi-dimensional OxCAP-MH capability instrument for outcome measurement in mental health: the German language version. BMC Psychiatry. (2018) 18:1-8. doi: 10.1186/s12888-018-1762-3

23. Kilian R, Bernert S, Matschinger H, Mory C, Roick C, Angermeyer MC. The standardized assessment of the need for treatment and support in severe mental illness: the development and testing of the German version of the Camberwell assessment of Need-EU. Psychiatr Prax. (2001) 28:S7983. doi: 10.1055/s-2001-17789

24. Phelan M, Slade M, Thornicroft G, Dunn G, Holloway F, Wykes T, et al. The Camberwell assessment of need: the validity and reliability of an instrument to assess the needs of people with severe mental illness. Br J Psychiatry. (1995) 167:589-95. doi: 10.1192/bjp.167.5.589

25. Reitan RM. Validity of the trail making test as an indicator of organic brain damage. Percept Mot Skills. (1958) 8:271-6. doi: 10.2466/pms.1958.8.3.271

26. Prinz U, Nutzinger DO, Schulz H, Petermann F, Braukhaus C, Andreas S. Comparative psychometric analyses of the SCL-90-R and its short versions in patients with affective disorders. BMC Psychiatry. (2013) 13:19. doi: 10.1186/1471-244X-13-104

27. Schäfer I, Gschwend C, Karow A, Naber D. Attitudes of patients with schizophrenia to psychiatric research. Int J Psychiatry Clin Pract. (2008) 12:165-70. doi: 10.1080/13651500701636502

28. Tallon D, Mulligan J, Wiles N, Thomas L, Peters TJ, Elgie R, et al. Involving patients with depression in research: survey of patients' attitudes to participation. Br J General Pract. (2011) 61:e134-41. doi: 10.3399/bjgp11X567036

29. Lakeman R, McAndrew S, MacGabhann L, Warne T. 'That was helpful... no one has talked to me about that before': research participation as a therapeutic activity. Int J Ment Health Nurs. (2013) 22:76-84. doi: 10.1111/j.1447-0349.2012.00842.x
30. Goossens I, Nicholls TL, Torchalla I, Brink J, de Ruiter C. The perceived impact of trauma-focused research on forensic psychiatric patients with lifetime victimization histories. J Empirical Res Human Res Ethics. (2016) 11:334-45. doi: 10.1177/1556264616670769

31. Kaminsky A, Roberts LW, Brody JL. Influences upon willingness to participate in schizophrenia research: an analysis of narrative data from 63 people with schizophrenia. Ethics Behav. (2003) 13:279-302. doi: 10.1207/S15327019EB1303_06

32. Haapea M, Miettunen J, Veijola J, Lauronen E, Tanskanen P, Isohanni M. Non-participation may bias the results of a psychiatric survey. Soc Psychiat Epidemiol. (2007) 42:403-9. doi: 10.1007/s00127-007-0178-Z

33. Andresen EL, Wilson KA, Castillo A, Koopman C. Patient motivation for participating in clinical trials for depression: validation of the motivation for clinical trials inventory-depression. Int Clin Psychopharmacol. (2010) 25:7-16. doi: 10.1097/YIC.0b013e328332055c

34. Marcantonio ER, Aneja J, Jones RN, Alsop DC, Fong TG, Crosby GJ, et al. Maximizing clinical research participation in vulnerable older persons: identification of barriers and motivators. J Am Geriatr Soc. (2008) 56:15227. doi: 10.1111/j.1532-5415.2008.01829.x

35. Chatland LE, Harvey C, Kelly K, Paradine S, Bhagat M, Hudson BF. Research participation in palliative medicine-benefits and barriers for patients and families: rapid review and thematic synthesis. BMJ Support Palliat Care. (2021) bmjspcare-2021-003093. doi: 10.1136/bmjspcare-2021-003093

36. Chong S-A, Ong YY, Subramaniam M, Abdin E, Marx CE, Campbell $\mathrm{AV}$. An assessment of the understanding and motivations of patients with schizophrenia about participating in a clinical trial. Contemp Clin Trials. (2009) 30:446-50. doi: 10.1016/j.cct.2009.04.006

37. Hofer A, Hummer M, Huber R, Kurz M, Walch T, Fleischhacker WW. Selection bias in clinical trials with antipsychotics. J Clin Psychopharmacol. (2000) 20:699-702. doi: 10.1097/00004714-200012000-00019

38. Nazemi H, Larkin AA, Sullivan MD, Katon W. Methodological issues in the recruitment of primary care patients with depression. Int J Psychiatry Med. (2001) 31:277-88. doi: 10.2190/Q8BW-RAA7-F2H3-19BF

39. Chin A, Markey A, Bhargava S, Kassam KS, Loewenstein G. Bored in the USA: experience sampling and boredom in everyday life. Emotion. (2017) 17:359. doi: $10.1037 / \mathrm{emo} 0000232$

40. Cross CP, Cyrenne D-LM, Brown GR. Sex differences in sensation-seeking: a meta-analysis. Sci Rep. (2013) 3:1-5. doi: 10.1038/srep02486

41. Vodanovich SJ, Kass SJ, Andrasik F, Gerber W-D, Niederberger U, Breaux C. Culture and gender differences in boredom proneness. North Am J Psychol. (2011) 13:221-30.

42. Segal SP, VanderVoort DJ. Daily hassles and health among persons with severe mental disabilities. Psychosoc Rehabil J. (1993) 16:27. doi: 10.1037/h0095677

43. Newell SE, Harries P, Ayers S. Boredom proneness in a psychiatric inpatient population. Int J Soc Psychiatr. (2012) 58:488-95. doi: 10.1177/0020764011408655

44. Gerritsen CJ, Goldberg JO, Eastwood JD. Boredom proneness predicts quality of life in outpatients diagnosed with schizophrenia-spectrum disorders. Int $J$ Soc Psychiatr. (2015) 61:781-7. doi: 10.1177/0020764015584647

45. Masland SR, Shah TV, Choi-Kain LW. Boredom in borderline personality disorder: a lost criterion reconsidered. Psychopathology. (2020) 53:23953. doi: $10.1159 / 000511312$

46. Boggs DL, Kelly DL, Liu F, Linthicum JA, Turner H, Schroeder JR, et al. Cannabis withdrawal in chronic cannabis users with schizophrenia. J Psychiatr Res. (2013) 47:240-5. doi: 10.1016/j.jpsychires.2012.10.010

47. Levy MS. Listening to our clients: the prevention of relapse. J Psychoactive Drugs. (2008) 40:167-72. doi: 10.1080/02791072.2008.10400627

48. Kuerbis A, Padovano HT, Shao S, Houser J, Muench FJ, Morgenstern J. Comparing daily drivers of problem drinking among older and younger adults: an electronic daily diary study using smartphones. Drug Alcohol Depend. (2018) 183:240-6. doi: 10.1016/j.drugalcdep.2017.11.012

49. Borge L, Martinsen EW, Ruud T, Watne Ø, Friis S. Quality of life, loneliness, and social contact among long-term psychiatric patients. Psychiatric Services. (1999) 50:81-4. doi: 10.1176/ps.50.1.81

50. Watson J, Fossey E, Harvey C. A home but how to connect with others? A qualitative meta-synthesis of experiences of people with mental illness living in supported housing. Health Soc Care Community. (2019) 27:54664. doi: $10.1111 / \mathrm{hsc} .12615$ 
51. Wang J, Lloyd-Evans B, Marston L, Mann F, Ma R, Johnson S. Loneliness as a predictor of outcomes in mental disorders among people who have experienced a mental health crisis: a 4 -month prospective study. BMC Psychiatry. (2020) 20:1-15. doi: 10.1186/s12888-020-02665-2

52. Woodall A, Morgan C, Sloan C, Howard L. Barriers to participation in mental health research: are there specific gender, ethnicity and age related barriers? BMC Psychiatry. (2010) 10:1-10. doi: 10.1186/1471-244X-10-103

53. Carey MP, Morrison-Beedy D, Carey KB, Maisto SA, Gordon CM, Pedlow CT. Psychiatric outpatients report their experiences as participants in a randomized clinical trial. J Nerv Ment Dis. (2001) 189:299. doi: 10.1097/00005053-200105000-00005

54. Bracken-Roche D, Bell E, Racine E. The "vulnerability" of psychiatric research participants: why this research ethics concept needs to be revisited. Can J Psychiatr. (2016) 61:335-9. doi: 10.1177/0706743716 633422

55. Alexander S, Pillay R, Smith B. A systematic review of the experiences of vulnerable people participating in research on sensitive topics. Int J Nurs Stud. (2018) 88:85-96. doi: 10.1016/j.ijnurstu.2018.08.013

56. Howard L, Ulucanlar SE, Thornicroft G, Donovan JL. An investigation into recruitment difficulties in an RCT of supported employment for people with severe mental illness. Contemp Clin Trials. (2009) 30:406. doi: 10.1016/j.cct.2008.07.007

57. Hughes-Morley A, Young B, Waheed W, Small N, Bower P. Factors affecting recruitment into depression trials: systematic review, metasynthesis and conceptual framework. J Affect Disord. (2015) 172:27490. doi: 10.1016/j.jad.2014.10.005
58. Schmier JK, Halpern MT. Patient recall and recall bias of health state and health status. Expert Rev Pharmacoecon Outcomes Res. (2004) 4:15963. doi: 10.1586/14737167.4.2.159

59. Wenemark M, Hollman Frisman G, Svensson $T$, Kristenson $M$. Respondent satisfaction and respondent burden among differently motivated participants in a health-related survey. Field Methods. (2010) 22:378-90. doi: 10.1177/1525822X10376704

Conflict of Interest: The authors declare that the research was conducted in the absence of any commercial or financial relationships that could be construed as a potential conflict of interest.

Publisher's Note: All claims expressed in this article are solely those of the authors and do not necessarily represent those of their affiliated organizations, or those of the publisher, the editors and the reviewers. Any product that may be evaluated in this article, or claim that may be made by its manufacturer, is not guaranteed or endorsed by the publisher.

Copyright (C) 2022 Dehn, Driessen, Steinhart and Beblo. This is an open-access article distributed under the terms of the Creative Commons Attribution License (CC BY). The use, distribution or reproduction in other forums is permitted, provided the original author(s) and the copyright owner(s) are credited and that the original publication in this journal is cited, in accordance with accepted academic practice. No use, distribution or reproduction is permitted which does not comply with these terms. 